\title{
Bone-protective effects of bioactive fractions and ingredients in Sambucus williamsii HANCE
}

\author{
Hui-Hui Xiao ${ }^{1}$, Yi Dai ${ }^{2}$, Hoi-Ying Wan ${ }^{3}$, Man-Sau Wong ${ }^{3,4_{*}}$ and Xin-Sheng Yao ${ }^{1,2 *}$ \\ ${ }^{1}$ School of Chinese Materia Medica, Shenyang Pharmaceutical University, Shenyang 110016, People's Republic of China \\ ${ }^{2}$ Institute of Traditional Chinese Medicine and Natural Products, College of Pharmacy, Jinan University, Guangzhou \\ 510632, People's Republic of China \\ ${ }^{3}$ Department of Applied Biology and Chemical Technology, The Hong Kong Polytechnic University, Hung Hom, Kowloon, \\ Hong Kong, People's Republic of China \\ ${ }^{4}$ Shenzhen Research Institute of The Hong Kong Polytechnic University, State Key Laboratory of Chinese Medicine and \\ Molecular Pharmacology, Shenzhen 518057, People's Republic of China
}

(Received 10 January 2011 - Revised 5 April 2011 - Accepted 6 April 2011 - First published online 21 June 2011)

\begin{abstract}
Our previous study demonstrated that $60 \%$ ethanol crude extract of Sambucus williamsii HANCE (SWH) improved bone mass, bone strength and bone micro-structure in both ovariectomised (OVX) rats and mice. The present study aims to identify the bioactive fractions and ingredients in SWH that account for its osteoprotective effects. Bilateral sham-operated mice acted as controls. OVX C57BL/6J mice, aged 12 weeks, were orally administrated daily with vehicle or $17 \beta$-oestradiol $(3 \cdot 2 \mathrm{mg} / \mathrm{kg}), \mathrm{SWH}(60 \%$ ethanol crude extract; $1 \cdot 0 \mathrm{~g} / \mathrm{kg}), \mathrm{SWA}$ (water eluate; $0.570 \mathrm{~g} / \mathrm{kg}$ ), SWB (30\% ethanol eluate; $0 \cdot 128 \mathrm{~g} / \mathrm{kg}$ ) or SWC (50 and $95 \%$ ethanol eluates; $0 \cdot 189 \mathrm{~g} / \mathrm{kg}$ ) for $12 \mathrm{weeks}$. The effects of the different fractions on bone properties in the OVX mice model were studied. In addition, their effects on osteoblast proliferation and differentiation were evaluated in UMR 106 cells. SWC significantly restored bone mineral density and improved bone size and bone content parameters in the femur and tibia as well as increased biomechanical strength at the tibia diaphysis in OVX mice. Similarly, SWC was the most potent fraction in stimulating cell proliferation and differentiation in UMR 106 cells. Also, SWC did not alter uterus weight in OVX mice. Nine major peaks, seven lignans and two phenolic acids, in the HPLC fingerprint of the SWC fraction were identified, isolated and characterised. In conclusion, the present study demonstrated that SWC was the most potent fraction in SWH that exerted antiosteoporotic effects. Furthermore, lignans might be the potential bioactive components in SWC.
\end{abstract}

Key words: Osteoporosis: Lignans: Sambucus williamsii HANCE: Phyto-oestrogens

Osteoporosis is a skeletal disorder of reduced bone mass and disruption of bone architecture with a consequent increase in bone fragility and fracture risk ${ }^{(1)}$. The decline of gonadal function following menopause and ageing plays a key role in the pathogenesis of osteoporosis. With a worldwide increase in ageing populations, osteoporosis has become a more serious global health problem. Hormone replacement therapy was a routine method to alleviate physical symptoms and to prevent the clinical consequence of postmenopausal osteoporosis ${ }^{(2)}$. However, recent studies suggest that hormone replacement therapy is associated with an increased risk of developing breast, ovarian and endometrial cancers ${ }^{(3-6)}$. This has led to increased interest in identifying natural oestrogen analogues that possess osteoprotective effects without any side effects on reproductive tissues. A class of plant-derived substances, the so-called 'phyto-oestrogens', has been reported to possess structures similar to mammalian oestrogens and display both oestrogenic and anti-estrogenic effects ${ }^{(7-8)}$. Isoflavones, lignans and cumestans are the major classes of phytooestrogen $^{(7)}$. Numerous studies on isoflavones in preventing the loss of bone mineral density (BMD) have been reported $^{(9,10)}$, while those that focus on the bone-protective effects of lignans and cumestans are few.

Sambucus williamsii HANCE (SWH), one species of Sambucus distributed in various regions of China, Korea and Japan, has been used as a folk medicine to treat bone and

Abbreviations: BMD, bone mineral density; BV/TV, bone volume/tissue volume; 3D, three-dimensional; $\mathrm{E}_{2}$, $17 \beta$-oestradiol; OVX, ovariectomised; Sham, sham-operated vehicle-treated; SWA, Sambucus williamsii HANCE water eluate; SWB, Sambucus williamsii HANCE $30 \%$ ethanol eluate; SWC, Sambucus williamsii HANCE 50 and 95\% ethanol eluates; SWH, Sambucus williamsii HANCE; Tb.N, trabecular bone number; Tb.Sp, trabecular bone separation.

*Corresponding authors: Dr Man-Sau Wong, fax + 852 23649932, email bcmswong@polyu.edu.hk; Professor Xin-Sheng Yao, fax + 86 20 85225849, email yaoxinsheng@vip.tom.com 
group; $n 8 ; 0 \cdot 128 \mathrm{mg} / \mathrm{g}$ body weight per d); SWC (50 and $95 \%$ ethanol eluates group; $n 8 ; 0 \cdot 189 \mathrm{mg} / \mathrm{g}$ body weight per $\mathrm{d}$ ). The solutions of SWH and its fractions were freshly prepared as SWH $(100 \mathrm{mg} / \mathrm{ml})$, SWA $(57 \mathrm{mg} / \mathrm{ml})$, SWB $(12 \cdot 8 \mathrm{mg} / \mathrm{ml})$ and SWC $(18.9 \mathrm{mg} / \mathrm{ml})$, and were given daily to mice. A phytooestrogen-free diet was applied in the present study to eliminate interactions between diet and fractions of $\mathrm{SWH}$ that had been reported in our previous study ${ }^{(13)}$. Drug treatment started 2 weeks after the surgery and was administrated orally through a gastric tube for 3 months. At the end of the treatment, the mice were killed, blood was withdrawn from the abdominal aorta and serum was prepared. From each animal, the uterus was collected, weighed and then stored at $-80^{\circ} \mathrm{C}$. The left femur and tibia were dissected and cleaned of all soft tissue, then wrapped in gauze saturated with PBS buffer, sealed in Eppendorf tubes and stored at $-20^{\circ} \mathrm{C}$ for further analysis. The animal study protocols were approved by the Animal Ethics Committee of The Hong Kong Polytechnic University.

\section{Micro-computed tomography analysis of bone properties}

The distal metaphysis of femur and the proximal metaphysis of tibia were scanned with a high-resolution micro vivaCT 40 system (Scanco Medical, Bassersdorf, Switzerland). The distal and proximal site was defined as $2.0 \mathrm{~mm}$ away from the femur end and tibia head. After images were captured, twenty out of 100 slices were chosen and established as the volume of interest. Trabecular bone was separated from cortical bone by free drawing regions using the software provided with the scanner. Then three-dimensional (3D) modelling was generated and morphological date of the sample was evaluated using a script-based 3D volume analysis tool IPL (Image Processing Language; Scanco Medical; http://www. scanco.ch/systems-solutions/software.html). 3D parameters for trabecular bone were obtained as follows: (1) bone volume/tissue volume (BV/TV); (2) trabecular bone number (Tb.N); (3) trabecular bone separation (Tb.Sp); (4) BMD.

\section{Three-point bending test}

The left tibias were cleaned to remove their surrounding soft tissue before the test. A three-point bending machine (model H10KM; Hounsfield Test Equipment Limited, Redhill, Surrey, UK) was used to determine the mechanical strength on the mid-shaft of the left tibia ${ }^{(18)}$. The two supporting points were fixed $4 \mathrm{~mm}$ apart with a single central loading point. A load was applied on the mid-shaft with a deformation rate of $2.0 \mathrm{~mm} / \mathrm{min}$ and a load-deformation curve was plotted simultaneously until the specimen was broken. Bending stiffness was calculated as the slope of the linear part of the loading-deformation curve.

\section{Cell culture}

UMR 106 cells were cultured in Dulbecco's modified Eagle's medium with $10 \%$ fetal bovine serum, which was presupplemented with penicillin (100 units/ml) and streptomycin
(100 mg/ml). At 80-90\% confluence, the cells were seeded in a ninety-six-well microtitre plate with 4000 cells/well. After incubation for $48 \mathrm{~h}$, the culture medium was changed to phenol red-free Dulbecco's modified Eagle's medium with $1 \%$ charcoal-stripped fetal bovine serum for $24 \mathrm{~h}$. The cells were then treated with SWH fractions at $0 \cdot 1,1 \cdot 0,10$ or $100 \mu \mathrm{g} / \mathrm{ml}$ for 24 or $48 \mathrm{~h}$. The cells were cultured at $37^{\circ} \mathrm{C}$ in a humidified atmosphere of $95 \%$ air and $5 \% \mathrm{CO}_{2}$.

\section{Cell proliferation assay}

The proliferation effects of the fractions of SWH on the UMR 106 cell line were determined by the MTS colorimetric assay. After treating with SWH fractions $(0 \cdot 1$ to $100 \mu \mathrm{g} / \mathrm{ml})$ or vehicle for $24 \mathrm{~h}$ or $48 \mathrm{~h}$, the medium was removed, followed by the addition of $0 \cdot 2 \mathrm{mg} / \mathrm{ml} \mathrm{3-(4,5-dimethylthiazol-2-yl)-5-(3-car-}$ boxymethoxyphenyl)-2-(4-sulfophenyl)-2H-tetrazolium (MTS; Promega Corp., Madison, WI, USA) and $1 \mathrm{mg} / \mathrm{ml}$ phenazine methosulfate (PMS; Sigma-Aldrich, St Louis, MO, USA) reagent. The absorbance was detected on a microplate spectrophotometer (model 680; Bio-Rad, Hercules, CA, USA) at a wavelength of $490 \mathrm{~nm}$ after $2 \mathrm{~h}$ of incubation at $37^{\circ} \mathrm{C}$.

\section{Alkaline phosphatase activity assay}

Alkaline phosphatase activity of the treated cells was determined by the hydrolysis of $p$-nitrophenylphosphate (Promega Corp.) to $p$-nitrophenol to assess the differentiation activity of UMR 106 cells. The treated cells were rinsed with PBS twice before $100 \mu \mathrm{l} p$-nitrophenylphosphate were added to them. Absorbance of the tested samples was measured at $405 \mathrm{~nm}$. All results are expressed as a ratio normalised to the corresponding total protein content (optical density at $405 \mathrm{~nm} / \mu \mathrm{g}$ BSA).

\section{Statistical analysis}

The data from these experiments are reported as mean values with their standard errors for each group. All statistical analyses were performed using PRISM version 5.0 (GraphPad, San Diego, CA, USA). Inter-group differences were analysed by one-way ANOVA, and followed by Tukey's multiplecomparison test as a post hoc test to compare the group mean if overall $P<0.05$. Differences of $P<0.05$ were considered statistically significant.

\section{Results}

\section{Body weight, uterine weight and serum biochemical makers}

The effects of SWH fractions on body weight, uterus index and serum biochemical makers are summarised in Supplementary Appendix 1 (available online at http://www.journals. cambridge.org/bjn). As expected, body weight increased significantly $(P<0.05)$ and uterus index decreased significantly $(P<0.05)$ in OVX mice as a result of oestrogen deficiency. Treatment of OVX mice with SWH or SWC extracts significantly 
suppressed oestrogen deficiency-induced body-weight gain (v. OVX group, both $P<0 \cdot 001)$. Uterus indexes were significantly increased in OVX mice in response to treatment with $\mathrm{E}_{2}$ or SWH. However, uterus indexes of the mice treated with the fractions of SWH did not alter as compared with those treated with vehicle. Serum Ca level and P levels were not altered by OVX or fractions of SWH.

\section{Micro-computed tomography analysis of left femur and tibia}

As shown in Table 3, ovariectomy significantly reduced BMD at the distal metaphysis of femur $(P<0.05 v$. sham $)$ and the proximal metaphysis of tibia $(P<0.05 v$. sham $)$ in mice. Treatment of OVX mice with $\mathrm{E}_{2}$ prevented the decrease in BMD at both sites $(P<0.001 v$. OVX). Similarly, treatment of OVX mice with SWH or SWC significantly restored BMD at the femur and tibia. Trabecular bone microstructure, as indicated by parameters such as BV/TV, Tb.N and Tb.Sp at the distal metaphysis of femur and at the proximal metaphysis of tibia deteriorated significantly in mice upon ovariectomy (Table 3; $P<0.05$ in all parameters at both sites). The damage of bone microstructure induced by ovariectomy in mice at the femur were reversed significantly by treatment with SWH $(P<0.01$ in BV/TV), SWA $(P<0.05$ in BV/TV) or SWC $(P<0.01$ in BV/TV, $P<0.01$ in Tb.N and $P<0.05$ in Tb.Sp) and at the tibia by treatment with SWH $(P<0.001$ in BV/TV, $P<0.05$ in Tb.N and $P<0.01$ in Tb.Sp) or SWC $(P<0.001$ in BV/TV, $P<0.05$ in Tb.N and $P<0.01$ in Tb.Sp). Among all the fractions of $\mathrm{SWH}$, the bone-protective effect of SWC was the same as or even higher than that of the total ethanol extract SWH. There were no differences of the trabecular bone parameters between Sham and the fraction-treated groups. The administration of SWH fractions restored the bone loss induced by ovariectomy to the normal level and maintained the microarchitecture of trabecular bone.

\section{Biomechanical measurement of left tibia}

Table 4 shows the effects of SWH fractions on the biomechanical properties of the left tibia in OVX mice. Three-point bending experiments indicated that treatment of OVX mice with $\mathrm{E}_{2}$ significantly increased the ultimate load $(P<0 \cdot 001)$, breaking force $(P<0.05)$ as well as stiffness $(P<0.05)$ of the tibia mid-shaft. Ultimate load of the left tibia mid-shaft were significantly increased in OVX mice in response to treatment with different SWH fractions, namely SWA $(P<0.05)$, SWB $(P<0.05)$ and SWC $(P<0.01)$. Breaking forces of the left tibia mid-shaft were increased significantly in OVX mice in response to treatment with SWC $(P<0 \cdot 01)$ while treatment with SWH did not show such effects on the breaking force. Stiffness of the tibia was only increased in OVX mice in response to treatment with SWA $(P<0 \cdot 05)$. Treatment of OVX mice with SWH fractions suppressed the OVX-induced reduction of ultimate load and stiffness in the tibia, resulting in an increase back to the Sham level. However, $E_{2}$ and all fractions of SWH had no significant effects on changes of energy of breaking.

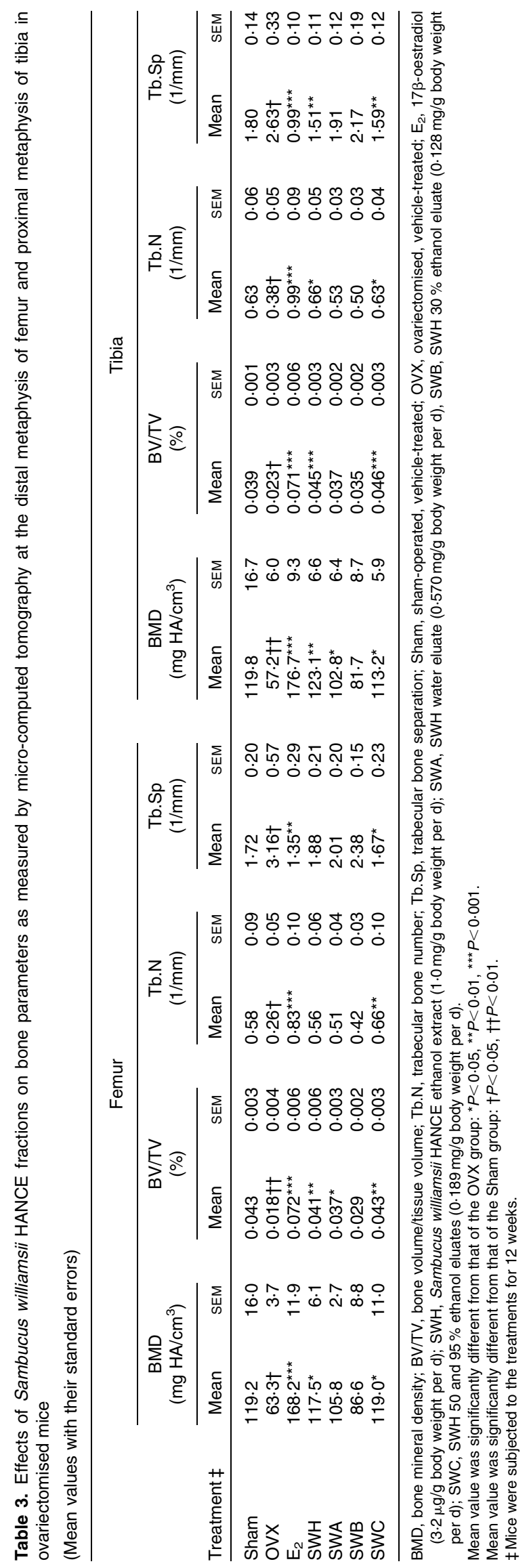


Table 4. Effects of Sambucus williamsii HANCE fractions on biomechanical properties of the left tibia in ovariectomised mice

(Mean values with their standard errors)

\begin{tabular}{|c|c|c|c|c|c|c|c|c|}
\hline \multirow[b]{2}{*}{ Treatmentł } & \multicolumn{2}{|c|}{$\begin{array}{l}\text { Ultimate } \\
\text { load (N) }\end{array}$} & \multicolumn{2}{|c|}{$\begin{array}{l}\text { Breaking } \\
\text { force }(\mathrm{N})\end{array}$} & \multicolumn{2}{|c|}{$\begin{array}{l}\text { Energy for breaking } \\
\qquad\left(\times 10^{-3} \mathrm{~J}\right)\end{array}$} & \multicolumn{2}{|c|}{$\begin{array}{l}\text { Stiffness } \\
(\mathrm{N} / \mathrm{mm})\end{array}$} \\
\hline & Mean & SEM & Mean & SEM & Mean & SEM & Mean & SEM \\
\hline Sham & $20 \cdot 83$ & 0.87 & $18 \cdot 57$ & 0.59 & $9 \cdot 82$ & 0.67 & $54 \cdot 31$ & $3 \cdot 1$ \\
\hline OVX & 17.93† & 0.48 & $15 \cdot 60 \dagger$ & 0.56 & $9 \cdot 06$ & 0.78 & 36.10† & $3 \cdot 23$ \\
\hline $\mathrm{E}_{2}$ & $23 \cdot 27^{\star \star \star}$ & 0.81 & $19 \cdot 74^{*}$ & 0.87 & $10 \cdot 20$ & $1 \cdot 12$ & $69 \cdot 00^{*}$ & $9 \cdot 43$ \\
\hline SWH & $19 \cdot 95$ & 0.47 & $17 \cdot 60$ & 0.56 & $9 \cdot 89$ & 0.60 & 61.48 & 7.94 \\
\hline SWA & $20 \cdot 90^{\star}$ & 0.76 & $17 \cdot 51$ & 0.74 & $9 \cdot 10$ & 0.98 & $69 \cdot 21^{*}$ & $7 \cdot 57$ \\
\hline SWB & $20 \cdot 97^{*}$ & 0.53 & $17 \cdot 48$ & $1 \cdot 15$ & 9.57 & $1 \cdot 31$ & $59 \cdot 40$ & 5.69 \\
\hline SWC & $21 \cdot 81^{\star \star}$ & 0.82 & $19 \cdot 72^{\star \star}$ & $1 \cdot 16$ & $9 \cdot 22$ & 0.88 & $61 \cdot 63$ & $10 \cdot 15$ \\
\hline
\end{tabular}

Sham, sham-operated, vehicle-treated; OVX, ovariectomised, vehicle-treated; $E_{2}, 17 \beta$-oestradiol ( $3 \cdot 2 \mu \mathrm{g} / \mathrm{g}$ body weight per d); SWH, Sambucus williamsii HANCE ethanol extract (1.0 mg/g body weight per d); SWA, SWH water eluate $(0.570 \mathrm{mg} / \mathrm{g}$ body weight per d), SWB, SWH $30 \%$ ethanol eluate $(0.128 \mathrm{mg} / \mathrm{g}$ body weight per d); SWC, SWH 50 and $95 \%$ ethanol eluates $(0.189 \mathrm{mg} / \mathrm{g}$ body weight per d).

Mean value was significantly different from that of the OVX group: ${ }^{\star} P<0.05,{ }^{\star \star} P<0.01,{ }^{\star \star \star} P<0.001$

Mean value was significantly different from that of the Sham group: $† P<0.05$

$\ddagger$ Mice were subjected to the treatment for 12 weeks.

\section{Rat osteoblast-like UMR 106 cell proliferation and differentiation assay}

Fig. 1(a) shows that treatment of rat osteoblast-like UMR 106 cells with SWH at $1 \mu \mathrm{g} / \mathrm{ml}$ for 24 and $48 \mathrm{~h}$ significantly increased cell proliferation $(P \leq 0 \cdot 001)$. The stimulatory effects of SWA, SWB and SWC (Fig. 1(b), (c), (d)) on UMR 106 cell proliferation were more potent than the effects of SWH (Fig. 1(a)). Treatment of UMR 106 cells with $0 \cdot 1$ to $100 \mu \mathrm{g} / \mathrm{ml}$ of SWA (Fig. 1(b)) or SWC (Fig. 1(d)) for 24 or $48 \mathrm{~h}$ significantly increased cell proliferation at all concentrations. SWB at 10 or $100 \mu \mathrm{g} / \mathrm{ml}$ (Fig. 1(c)) significantly increased UMR 106 cell proliferation. To determine the effects of different $\mathrm{SWH}$ extracts on osteoblastic cell differentiation, alkaline phosphatase activities in UMR 106 cells in response to different concentrations of SWH, SWA, SWB and SWC were measured. As observed with $\mathrm{E}_{2}$, SWH (Fig. 2(a)) and SWB (Fig. 2(c)) significantly promoted cell differentiation activity at $0.1 \mu \mathrm{g} / \mathrm{ml}$ (both $P<0.05$ ), while SWA (Fig. 2(b)) had no effects on cell differentiation. SWC (Fig. 2(d)) significantly increased cell alkaline phosphatase activity at all concentrations $(0 \cdot 1$ to $100 \mu \mathrm{g} / \mathrm{ml})$, especially at $1 \mu \mathrm{g} / \mathrm{ml}(122 \cdot 8 \%)$, which was higher than the increased level upon treatment with $\mathrm{E}_{2}(112 \cdot 4 \%)$.

\section{Identification of components in Sambucus williamsii HANCE 50 and $95 \%$ ethanol eluate}

The peaks of the HPLC fingerprint of SWC (Supplementary Appendix 2; available online at http://www.journals. cambridge.org/bjn) characterised with the compounds isolated from SWC were as follows: peak $1(16.8 \mathrm{~min}$, vanillic acid); peak 2 (22.7 min, coniferyl alcohol); peak 3 (28.3 min, (+)-erythro-1-(4-hydroxy-3-methoxyphenyl)-2-[4-(3-hydroxypropanyl)-2-methoxy-phenoxy]-1, 3-propanediol); peak 4 (29.3 min, (+)-thero-1-(4-hydroxy-3-methoxyphenyl)-2-[4-(3hydroxypropanyl)-2-hydro-phenoxy]-1,3-propanediol); peak 5 (29.9 min, (+)-thero-guaiacylglycerol- $\beta$-O- $4^{\prime}$-conifery ether); peak 6 (31.0 min, (+)-erythro-1-(4-hydroxy-3-methoxyphenyl)-2-[-4-(3-hydroxypropanyl)-2-methoxy-phenoxy]-1,3propanediol); peak 7 (40.4 min, (+)-lariciresinol); peak 8 ( $42.1 \mathrm{~min}$, dehydrodiconiferylalcohol); peak 9 (42.8 min, dihydrodehydrodiconiferyl alcohol). The sum of peak areas of peaks 1 to 9 occupied $87.0 \%$ of the total peak areas.

\section{Discussion}

The present study systematically evaluated the osteoprotective effects of different fractions of SWH in OVX mice and in rat osteoblast-like UMR 106 cells. The present results clearly demonstrated that the 50 and $95 \%$ ethanol eluates (SWC) of the ethanol extract of SWH suppressed OVX-induced loss in bone mass and bone strength and increase in body weight. Besides, SWC did not alter the uterus weight in OVX mice. Moreover, the present study showed that SWC effectively promoted proliferation and differentiation in UMR 106 cells. In addition, the present study identified that the major components isolated from SWC were lignans, which may account for the osteoprotective effects of this fraction or even this herb.

Our recent study ${ }^{(13)}$ reported that a $60 \%$ ethanol extract of SWH dose-dependently increased BMD but only a high-dose treatment group showed statistically significant differences compared with OVX mice. To investigate if further fractions of SWH may lead to more potent protective effects in bone, SWH was separated with a macroporous adsorptive resin column and three fractions were obtained. The boneprotective effects of the fractions and $\mathrm{SWH}$ were evaluated and were compared using in vivo and in vitro results.

Trabecular bone mass, trabecular bone microstructure and cortical bone biomechanical strength are three key aspects associated with bone properties and turnover ${ }^{(19)}$. Micro-computed tomography measurement showed that SWH improved trabecular BMD and suppressed disruption of trabecular bone microstructure of the femur and tibia in OVX mice, 

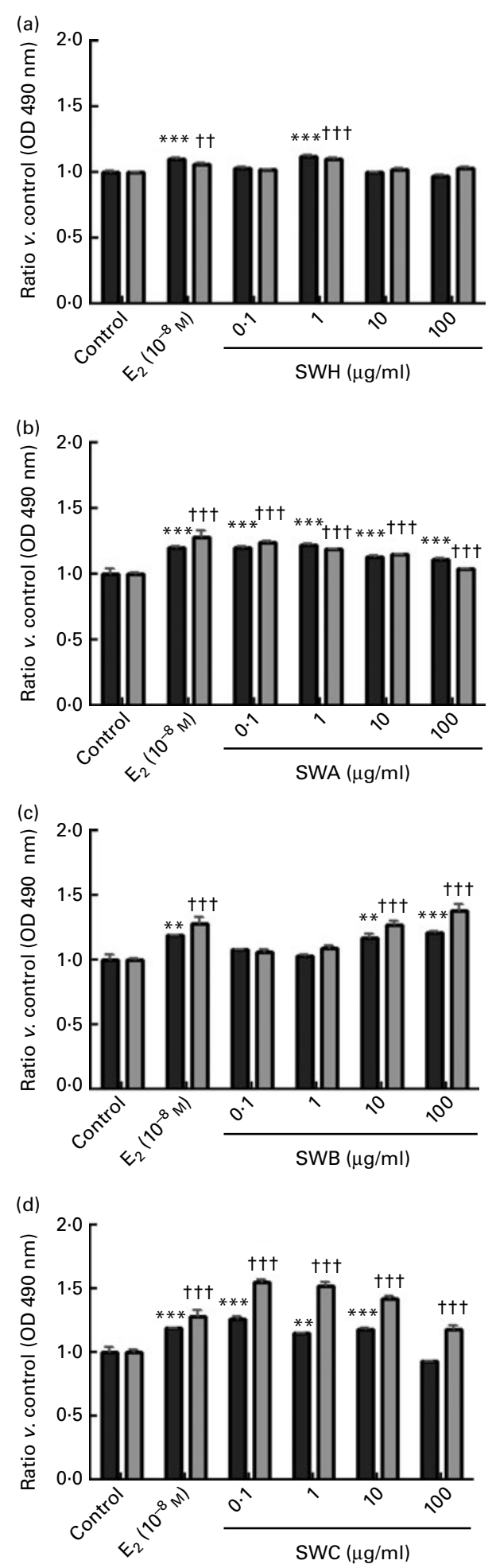

Fig. 1. Effects of (a) Sambucus williamsii HANCE (SWH), (b) Sambucus williamsii HANCE water eluate (SWA), (c) Sambucus williamsii HANCE 30\% ethanol eluate (SWB) and (d) Sambucus williamsii HANCE 50 and $95 \%$ ethanol eluates (SWC) on cell proliferation in rat osteoblast-like UMR 106 cells. ( $\square$ ), $24 \mathrm{~h}$; $(\square), 48 \mathrm{~h}$; OD, optical density. Results were obtained from three independent experiments. Values are means, with standard errors represented by vertical bars. Mean value was significantly different from that of the control $(24 \mathrm{~h}):{ }^{* *} P<0.01,{ }^{* * *} P<0.001$. Mean value was significantly different from that of the control (48h): †† $P<0.01$, ††† $P<0.001$. a result that is in accordance with our previous study ${ }^{(12,13)}$ The fractions obtained from further fractionations of $\mathrm{SWH}$ (i.e. SWA and SWC) did inhibit bone mineral loss induced by ovariectomy. In particular, the protective effects of SWC on trabecular bone in OVX mice were comparable with the effects of SWH. Moreover, micro-architectural parameters such as BV/TV, Tb.N and Tb.Sp of trabecular bone at the distal metaphysis of femur and the proximal metaphysis of tibia in OVX mice were significantly improved by treatment with SWC and the improvement was even higher than brought about by SWH. The results of three-point bending experiments on tibial cortical bone demonstrated that all fractions of SWH could significantly increase the ultimate load of the tibia diaphysis. Furthermore, the SWC treatment significantly increased breaking force and SWA treatment significantly increased stiffness in OVX mice. These results indicated that all fractions of SWH significantly improved the biomechanical strength of the long bone in OVX mice. The analysis of micro-computed tomography and three-point bending tests suggested that SWC may contain nearly all (87\%) of the active ingredients of SWH that account for its protective effects on bone mass and bone quality.

SWH extract inhibited bone resorption by suppressing osteoclastogenesis via modulation of the osteoprotegerin: receptor activator of $\mathrm{NF}-\kappa \mathrm{B}$ ligand (OPG:RANKL) ratio in UMR 106 cells $^{(12)}$. To investigate the effects of different SWH fractions on osteoblastic cell function, the proliferation and differentiation of osteoblast-like UMR 106 cells were determined in the present study. The studies showed that SWH promoted cell proliferation and differentiation at 1 and $0 \cdot 1 \mu \mathrm{g} / \mathrm{ml}$, respectively. Fractions obtained from further fractionation of SWH stimulated osteoblastic cell proliferation and differentiation. Among the fractions, SWC showed very high potency for increasing cell proliferation and differentiation at doses from $0 \cdot 1$ to $100 \mu \mathrm{g} / \mathrm{ml}$. Our in vitro results confirmed the conclusion of the in vivo experiment that SWC was the fraction with the highest potency on bone protection and was enriched with most of the active ingredients in SWH that account for its ability to improve bone properties.

Our previous study found that the most effective dose $(1000 \mathrm{mg} / \mathrm{kg})$ of ethanol extract of SWH after conversion from animal to human dosage was $5.5 \mathrm{~g} / \mathrm{d}$ in women with a body weight of $50 \mathrm{~kg}^{(13)}$. Similarly, the treatment dose of SWC $(0.189 \mathrm{~g} / \mathrm{kg})$ applied in the present study for the improvement of bone properties will be $1.0 \mathrm{~g} / \mathrm{d}$ for postmenopausal women administered orally. The present finding revealed that a lower dose of SWC will be needed to obtain effects that are similar to or even better than SWH.

Oestrogen or substances with oestrogenic potential were previously shown to be able to attenuate ovariectomy-induced weight gain ${ }^{(19-21)}$. The present results showed that SWH and SWC significantly suppressed the body-weight gain induced by OVX, suggesting that SWH and SWC might also contain phyto-oestrogens. Similar to our previous study ${ }^{(13)}$, the present study confirmed that SWH stimulated the increase of uterus weight in OVX animals. In contrast to SWH, SWC did not alter uterus weight in OVX mice, suggesting that SWC did not exert undesirable oestrogen-like effects on the 

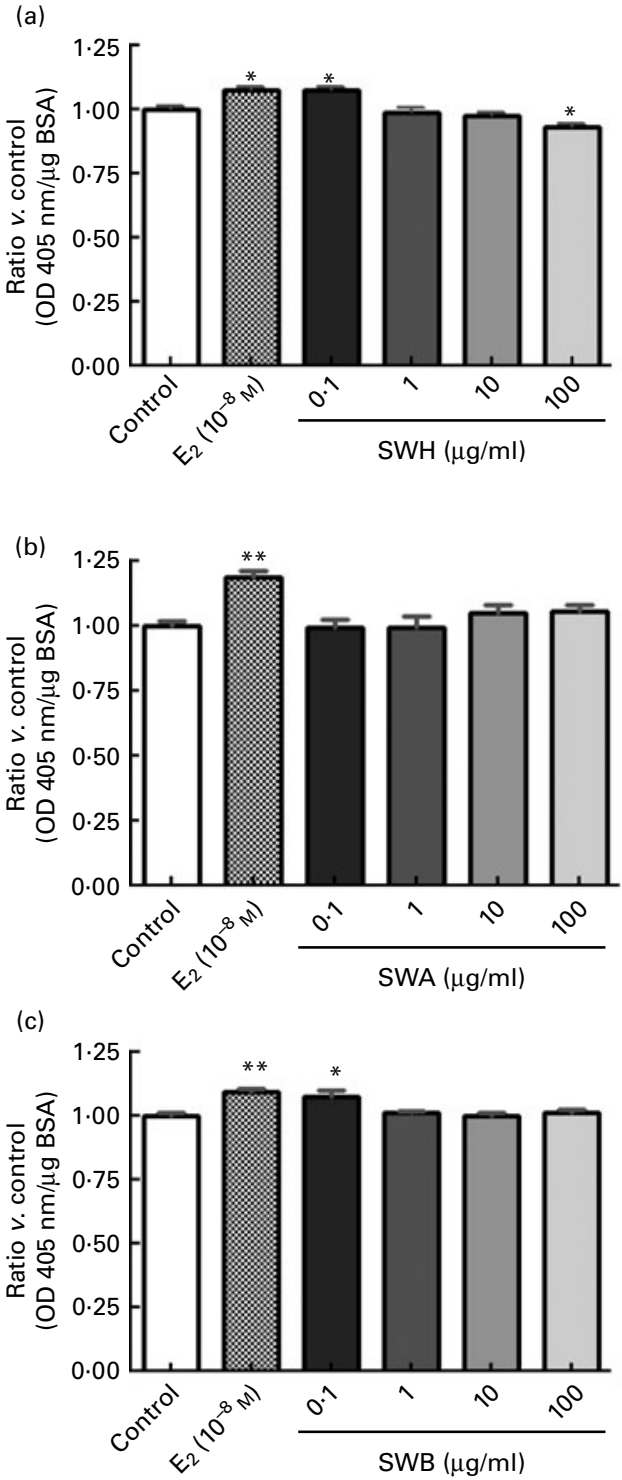

(d)

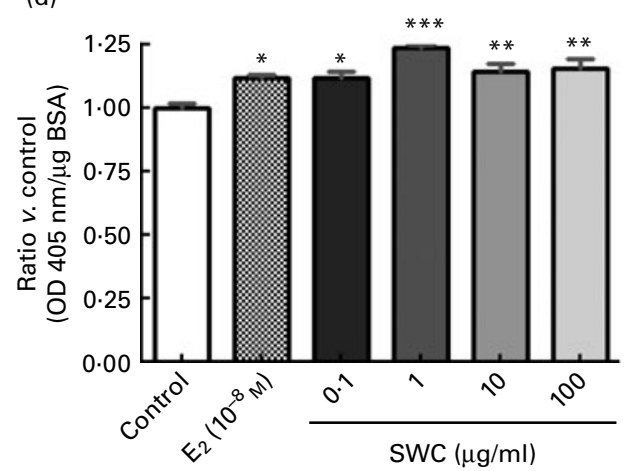

Fig. 2. Effects of (a) Sambucus williamsii HANCE (SWH), (b) Sambucus williamsii HANCE water eluate (SWA), (c) Sambucus williamsii HANCE $30 \%$ ethanol eluate (SWB) and (d) Sambucus williamsii HANCE 50 and $95 \%$ ethanol eluates (SWC) on cell differentiation activity in rat osteoblast-like UMR 106 cells. OD, optical density; BSA, bovine serum albumin. Results were obtained from three independent experiments. Values are means, with standard errors represented by vertical bars. Mean value was significantly different from that of the control: ${ }^{\star} P<0.05,{ }^{* \star} P<0.01,{ }^{\star \star \star} P<0.001$. reproductive system. Rachon et $a l^{(19-21)}$ found that daidzein and purarin at high doses $(1.0$ and $3.0 \mathrm{~g} / \mathrm{kg}$, respectively) exerted uterotropic effects on OVX rats. Our studies provide an exciting result for finding a new agent for bone protection without unsatisfactory effects on the uterus.

Phenolic acids $^{(15)}$, lignans ${ }^{(14,22)}$, triterpenoids $^{(16)}$ and some other compounds had been isolated from SWH in our previous study. However, the major active ingredients that account for its bone protection in vivo are still not known. In the present study, seven lignans and two phenolic acids, which are the major components in SWC, were identified. The results indicated that lignans might be the active ingredients in the SWH fraction that account for its bone-protective effects in vivo. However, the biological activities of these isolated compounds were been studied in the present investigation. Further study will be needed to confirm if these compounds can directly stimulate the growth and differentiation of bone cells as well as exert osteoprotective effects in vivo.

In conclusion, the present study revealed that SWC was the fraction of highest potency in SWH and that it could prevent bone loss, improve trabecular bone microstructure and increase cortical bone strength in OVX mice. Most importantly, the doses of SWC used in the present study can fully restore bone loss to the pre-OVX level. The in vitro experiments suggested that SWC might increase bone formation by promoting proliferation and differentiation of osteoblast-like cells. Most importantly, the effective dose of SWC to achieve similar bone-protective effects as SWH is found to be only one fifth of that of SWH. In addition, seven lignans and two phenolic acids, which are the major peaks of the HPLC fingerprint of SWC, were identified. Further studies are needed to characterise the mechanism by which the isolated lignans and phenolic acids exert anabolic effects on bone cells, presumably osteoblasts. The present study suggests that SWC needs to be investigated as a natural alternative for the management of postmenopausal osteoporosis.

\section{Acknowledgements}

The present study was supported by the Niche area Research Grant from the Research Committee of The Hong Kong Polytechnic University (I-BB8N, GU324, GU256) and the Shenzhen-Hong Kong Innovation Circle Funding Scheme (2006). We thank the support of the State Key Laboratory of Chinese Medicine and Molecular Pharmacology, HKSAR.

The authors' responsibilities were as follows: M.-S. W. and X.-S. Y. conceived of and designed the study and obtained funding; H.-H. X., Y. D. and H.-Y. W. implemented the study; H.-H. X. acquired and analysed the data, and wrote the manuscript; M.-S. W. and X.-S. Y. critically revised the manuscript and its intellectual content.

None of the authors had a conflict of interest.

\section{References}

1. Lock CA, Lecouturier J, Mason JM, et al. (2006) Lifestyle interventions to prevent osteoporotic fractures: a systematic review. Osteoporos Int 17, 20-28. 
2. Notelovitz M (1997) Estrogen therapy and osteoporosis: principles and practice. Am J Med Sci 313, 2-12.

3. Davison S \& Davis SR (2003) Hormone replacement therapy: current controversies. Clin Endocrinol 58, 249-261.

4. Beral V, Banks E, Reeves G, et al. (1999) Use of HRT and the subsequent risk of cancer. J Epidemiol Biostat 4, 191-210.

5. Persson I, Weiderpass E, Bergkvist L, et al. (1999) Risks of breast and endometrial cancer after estrogen and estrogen-progestin replacement. Cancer Causes Control 10, 253-260

6. Rodriguez C, Calle EE, Coates RJ, et al. (1995) Estrogen replacement therapy and fatal ovarian cancer. Am J Epidemiol 141, 828-835.

7. Albertazzi P \& Purdie DW (2002) The nature and utility of the phytoestrogens: a review of the evidence. Maturitas 42, 173-185.

8. Brzezinski A \& Debi A (1999) Phytoestrogens: the "natural" selective estrogen receptor modulators? Eur J Obstet Gynecol Reprod Biol 85, 47-51.

9. Fanti P, Monier-Faugere MC, Geng Z, et al. (1998) The phytoestrogen genistein reduces bone loss in short-term ovariectomized rats. Osteoporos Int 8, 274-281.

10. Scheiber MD, Liu JH, Subbiah MTR, et al. (2001) Dietary inclusion of whole soy foods results in significant reductions in clinical risk factors for osteoporosis and cardiovascular disease in normal postmenopausal women. Menopause $\mathbf{8}$, 384-392.

11. Song LR \& Hong X (editors) (2001) The Grand Dictionary of Modern Traditional Chinese Medicine, pp. 1927-1928. Peking: People's Health Press.

12. Xie F, Wu CF, Zhang Y, et al. (2005) Increase in bone mass and bone strength by Sambucus williamsii HANCE in ovariectomized rats. Biol Pharm Bull 28, 1879-1885.

13. Zhang Y, Li Q, Wan HY, et al. (2011) Study of the mechanisms by which Sambucus williamsii HANCE extract exert protective effects against ovariectomy-induced osteoporosis in vivo. Osteoporos Int 22, 703-709.
14. Yang XJ, Wong MS, Wang NL, et al. (2007) Lignans from the stems of Sambucus williamsii and their effects on osteoblastic UMR106 cells. J Asian Nat Prod Res 9, 583-591.

15. Yang XJ, Wong MS, Wang NL, et al. (2005) Effect of phenolic acids isolated from Sambucus williamsii on proliferation and differentiation of rat osteoblastic UMR106 cells. Chin Trad Herb Drugs 36, 1604-1607.

16. Yang XJ, Wang NL, Wong MS, et al. (2005) Studies of triterpenoids isolated from Sambucus willamsii Hance and their effects on UMR106 cell proliferation and alkaline phosphatase activity. J Shenyang Pharm Univ 22, 449-452, 457.

17. Chinese Materia Medica of State Administration of Traditional Chinese Medicine (2000) Chinese Bencao, pp. 545-547 [LR Song, editor]. Shanghai: Shanghai Science and Technology Press.

18. Pang WY, Wang XL, Mok SK, et al. (2010) Naringin improves bone properties in ovariectomized mice and exerts oestrogen-like activities in rat osteoblast-like (UMR-106) cells. Br J Pharmacol 159, 1693-1703.

19. Rachó́ D, Vortherms T, Seidlova-Wuttke D, et al. (2007) Effects of dietary equol on body weight gain, intra-abdominal fat accumulation, plasma lipids, and glucose tolerance in ovariectomized Sprague-Dawley rats. Menopause $\mathbf{1 4}$ 925-932.

20. Rachoń D, Vortherms T, Seidlova-Wuttke D, et al. (2007) Dietary daidzein and puerarin do not affect pituitary LH expression but exert uterotropic effects in ovariectomized rats. Maturitas 57, 161-170.

21. Rachoń D, Vortherms T, Seidlova-Wuttke D, et al. (2008) Effects of black cohosh extract on body weight gain, intra-accumulation, plasma lipids and glucose tolerance in ovariectomized Sprague-Dawley rats. Maturitas 60, 209-215.

22. Ou YF, Liu Y, Xiao HH, et al. (2009) Lignans from stems of Sambucus williamsii. China J Chin Mater Med 34, $1225-1227$. 